\title{
Group Discussions and Academic Performance: Exploring the Classroom Factors that Contribute to Student Success
}

\author{
Ryan L. Boyd ${ }^{1}$, James W. Pennebaker ${ }^{1}$, Jason D. Ferrell ${ }^{1}, \&$ Nickolay Georgiev $^{2}$ \\ ${ }^{1}$ The University of Texas at Austin, Dept. of Psychology \\ ${ }^{2}$ Norweigan Business School, Dept. of Marketing
}

Correspondence should be sent to the Ryan L. Boyd at the Department of Psychology A8000, 108 E. Dean Keaton, University of Texas, Austin, TX 78712; email: RyanBoyd@utexas.edu. Preparation of this manuscript was aided by grants from the Army Research Institute (W5J9CQ12C0043) and the National Science Foundation (IIS-1344257). The views, opinions, and/or findings contained in this report are those of the authors, and shall not be construed as official Department of the Army position, policy, or decision, unless so designated by other documents. 


\begin{abstract}
Do in-class discussion groups lead to improved learning for individual group members? Analyses of over 1600 students' language samples from $4800+$ online discussion groups revealed that markers of linguistic engagement were highly predictive of academic outcomes.
\end{abstract}

Keywords: language, groups, academic performance, engagement 


\section{Introduction}

For decades, researchers and educators have suggested that splitting students into learning groups in the classroom may lead to several benefits, including better academic performance (e.g., Kalaian \& Kasim, 2014). These benefits often appear to be far-reaching: student mood, student attendance, and even faculty attitudes have been shown to demonstrate marked improvements relative to more conventional methods of teaching (e.g., Vernon \& Blake, 1993). But what is the nature of these effects? Can such outcomes be explained by factors intrinsic to the students themselves, such as their engagement (e.g., Reeve, Jang, Carrell, Jeon, \& Barch, 2004)? In the current study, we investigate the broad nature of cooperative learning groups and how they relate to academic performance in the context of a large scale online educational platform. In doing so, we explore the links between the language and behaviors of discussion group members, how students engage in studying behaviors, individual difference factors, and academic performance. In sum, we sought to synthesize an incredibly diverse and rich data generated in an online learning environment into a more complete understanding of how students learn and, importantly, how students may best learn.

\section{Methodology}

\section{The TOWER Platform}

In the Fall of 2014, over 1,500 students enrolled and participated in an online introductory psychology course at the University of Texas at Austin. The course was built on an educational platform, TOWER, which was designed with research interests in mind (see Pennebaker, Gosling, \& Ferrell, 2013). TOWER behaves as an add-in module for the popular Canvas platform and expands its capabilities to recreate features of an in-person classroom, including real-time streaming lectures, chatrooms, and in-class exercises.

\section{Data Collection}

Throughout the semester, students were required to take daily quizzes ("benchmarks"), participate in randomly assigned group discussions, and complete several writing assignments. Across the semester, complete student data is collected pertaining to quiz performance, group interactions, self-report measures, and system navigation behaviors (i.e., timestamped link clicks). On most class days, students were randomly assigned to 4- and 5person groups ( $N=\sim 4,450$ groups) to discuss material from the lecture as a learning exercise. On three class days, group size served as an experimental manipulation whereby students were assigned to either 5-person discussion groups $(N=\sim 400$ groups, approximately 2,000 individuals) or to work alone by writing about the lecture material $(N=\sim 1900)$.

\section{Measures of Student Behaviors in Groups}

The complete language data from all discussions were logged, resulting in one of the largest academic datasets of group interactions/processes of its kind. We quantified the contents of group interactions in three separate ways. The first was to use a simple measure of group activity by means of calculating the total number of words said by each person within each group. The second was to examine the language of group discussions using a measure of thinking complexity revealed through language called the categorical-dynamic index (CDI). The complexity of thought, captured by the CDI, has been shown in the past to be a robust predictor 
of academic performance (Pennebaker, Chung, Frazee, LaVergne, \& Beaver, 2014). Finally, we quantified whether each student actively participated in each group ("chatting"), was present in the group but did not actively participate ("lurking"), or was wholly absent from each group activity ("absentee").

\section{Measures of Group Climate.}

Discussion group exercises were typically followed by asking students to complete of an interaction rating questionnaire (IRQ), which assessed the degree to which students felt the groups were productive and cohesive. Students responded to three questions on a scale from 1 to $5(M=3.33, S D=1.11)$, including how smooth the interaction went, how productive the interaction was, and how much they enjoyed the interaction.

\section{Measures of Group Effectiveness and Student Performance}

Many group discussions were immediately followed by a post-chat quiz to assess the degree to which students were able to help each other understand the newly-learned material. Additionally, the daily benchmark quizzes were completed at the beginning of each day's class as a broader measure of student learning and performance -- these scores were the primary basis for student grades in the course. Finally, we tracked the number of in-system clicks made by each student across the semester that occurred during non-class hours. These clicks generally reflected studying habits and non-mandatory learning behaviors on the part of students.

\section{Measure of Engagement}

As a secondary line of questioning, we sought to explore the degree to which another factor, student engagement, was predictive of the learning outcomes attributed to discussion groups that has been reported elsewhere. Engagement is commonly defined as an intrinsic motivation that leads to initiative-taking and other motivated behaviors (Reeve et al., 2004). Separate from the traditional classroom format, students were able to complete optional surveys that included personality inventories and demographic questionnaires, optional quizzes that did not impact grades, and participate in optional chatrooms prior to and following class. Since all three activities were optional and necessarily reflected students' motivation, engagement was calculated by factoring together the number of times each student participated in each of these three optional activities $($ alpha $=.72)$.

\section{Preliminary Results}

\section{One-versus Five-Person Groups}

Central to the current research is the question of whether 5-person groups offer a benefit over engaging in a similar task alone. For the three days where group-size manipulations occurred, we performed a 1-way ANOVA on IRQ scores (all three days) and post-chat quiz scores (days 1 and 3). Results are presented in Table 1. Generally speaking, students appeared to feel that the exercises involving 5-person groups were more productive and enjoyable. However, results were mixed regarding whether either condition showed a benefit over the other. 


\begin{tabular}{|l|l|l|l|}
\hline & Study 1 & Study 2 & Study 3 \\
\hline $\begin{array}{l}\text { Discussion } \\
\text { Category }\end{array}$ & $\begin{array}{l}\text { Conceptual problem } \\
\text { solving }\end{array}$ & $\begin{array}{l}\text { Conceptual } \\
\text { abstraction }\end{array}$ & Theory application \\
\hline Topic & $\begin{array}{l}\text { How to test if personality } \\
\text { is related to one of two } \\
\text { emotion theories }\end{array}$ & $\begin{array}{l}\text { What is needed to } \\
\text { know if animals have } \\
\text { personality }\end{array}$ & $\begin{array}{l}\text { What emotion theory best } \\
\text { explains falling in love at } \\
\text { a high altitude }\end{array}$ \\
\hline $\begin{array}{l}\text { Total } \\
\text { participants }\end{array}$ & 1,349 & 1,248 & 1,296 \\
\hline $\begin{array}{l}\text { 1-person } \\
\text { groups }\end{array}$ & 636 & 664 & 596 \\
\hline $\begin{array}{l}\text { 5-person } \\
\text { groups }\end{array}$ & 143 & 117 & $67.2 / 75.3^{*}$ \\
\hline $\begin{array}{l}\text { Post-chat } \\
\text { quiz }(1 / 5)\end{array}$ & $80.6 / 80.3$ & N/A & $3.18 / 3.41^{*}$ \\
\hline $\begin{array}{l}\text { Group } \\
\text { climate (1 / 5) }\end{array}$ & $2.94 / 2.68^{*}$ & $3.60 / 3.39 \#$ & \\
\hline
\end{tabular}

Table 1. Exploring the efficacy of 5-person discussion groups versus performing a similar thinking task in solo. ${ }^{*} \mathrm{p}<.05 ; \# \mathrm{p}=.07$

In order to examine group processes, we performed Pearson correlations between our two language-based measures of group interactions (word count and CDI) and the two outcome measures of interest (post-chat quiz scores and group climate). Results are presented in Table 2. The results suggest that, surprisingly, the thinking style of group interactions did not appear to consistently exhibit a relationship with either climate or group performance subsequent to group discussions. Rather, it appears that groups who simply interacted more also exhibited a tendency to perform better on post-chat quizzes pertaining to the discussed material.

\section{Student Engagement}

Results up to this point suggest that, while belonging to a discussion group feels more productive to students, subsequent performance does not appear to be consistently impacted by what transpired during group discussions. Rather, we see evidence that students who are more active in their group discussions tended to perform better on relevant post-chat quizzes. As a final analysis, we explored the degree to which student engagement was predictive of multiple student factors, including their overall performance, participation in group discussions, and studying behaviors. Results are presented in Table 3. 


\begin{tabular}{|l|c|c|c|}
\hline & $\begin{array}{c}\text { Study 1: } \\
\text { Conceptual problem } \\
\text { solving }\end{array}$ & $\begin{array}{c}\text { Study 2: } \\
\text { Conceptual } \\
\text { abstraction }\end{array}$ & $\begin{array}{c}\text { Study 3: } \\
\text { Theory } \\
\text { application }\end{array}$ \\
\hline CDI-quiz (a/b/c)* & $.04 / .01 / .02$ & N/A & $\mathbf{. 1 2 / - . 1 4 / - . 0 1 ~}$ \\
\hline CDI-climate & $\mathbf{. 1 9} / .03 / .05$ & $.02 /-.12 / .03$ & $\mathbf{. 1 2} /-.12 /-.04$ \\
\hline Word count - quiz & $\mathbf{. 1 9} / .27 / .17$ & $\mathrm{~N} / \mathrm{A}$ & $.08 / . \mathbf{2 1} / . \mathbf{1 1}$ \\
\hline $\begin{array}{l}\text { Word count - } \\
\text { climate }\end{array}$ & $\mathbf{. 4 7 / . 5 4 / . 1 3}$ & $\mathbf{. 4 6 / . 4 5 / . 2 4}$ & $\mathbf{. 3 9 / . 4 8 / . 1 9}$ \\
\hline
\end{tabular}

Table 2: Group process relationships with performance and climate.

$*$ Correlations in bold are significant, $\mathrm{p}<.01$.

$\mathrm{a}=$ correlation for individuals in the 1-person group, $\mathrm{r}>.10, \mathrm{p}<.01$

$\mathrm{b}=$ correlation for groups in the 5-person group at group level, $\mathrm{r}=.21, \mathrm{p}<.01$

$\mathrm{c}=$ correlation for groups in the 5-person group at individual level, $\mathrm{r}>.10, \mathrm{p}<.01$

\begin{tabular}{|l|c|c|c|c|}
\hline & Engagement & Grade & Chatting & Clicks \\
\hline Grade & .38 & -- & -- & -- \\
\hline Group Participation & .81 & .35 & -- & -- \\
\hline Studying Behaviors & .50 & .39 & .33 & -- \\
\hline Group Climate Ratings & .19 & .05 & .21 & .05 \\
\hline
\end{tabular}

Table 3. Correlations between engagement and student factors, including group participation, studying behaviors (clicking during non-class hours), and perceptions of group climates. Grade=final grade in course; Group Participation=percent of chats where student actively participated; Studying Behaviors=number of class-related page visits during non-class hours; Group Climate Ratings=self-reported IRQ. $N$ s range from 1,446 to 1,523. All $r$ 's $>.19, \mathrm{p}$ $<.0001$.

\section{Conclusions}

We return to our original question: Do in-class discussion groups lead to improved learning outcomes for individual group members? Across analyses of group membership, group processes, and engagement, we find no consistent evidence that splitting students into small groups to discuss class-relevant material is linked to improved student learning or performance on quizzes designed to directly assess successful learning of material in groups. Rather, the most consistent results in this realm are that group membership is associated with perceptions of productivity and enjoyment. However, our final analysis suggests that a factor intrinsic to 
students -- their engagement with the course and learning process -- is strongly predictive of students' final grades, their in-class behaviors (group participation), out-of-class behaviors (studying in off-hours), and how they generally perceive the group exercises (IRQ). 


\section{Key References}

Kalaian, S. A., \& Kasim, R. M. (2014). A meta-analytic review of studies of the effectiveness of small-group learning methods on statistics achievement. Journal of Statistics Education, 22(1), 1-20.

Pennebaker, J. W., Chung, C. K., Frazee, J., LaVergne, G. M., \& Beaver, D. I. (2014). The smallest words can predict academic success: The case of college admissions essays. PLoS ONE, 9(12). http://dx.plos.org/10.1371/journal.pone.0115844

Pennebaker, J. W., Gosling, S. D., \& Ferrell, J. D. (2013). Daily online testing in large classes: Boosting college performance while reducing achievement gaps. PLOS ONE, 8(11). http://dx.doi.org/10.1371/journal.pone.0079774

Reeve, J., Jang, H., Carrell, D., Jeon, S., \& Barch, J. (2004). Enhancing students' engagement by increasing teachers' autonomy support. Motivation and Emotion, 28(2), 147-169.

Vernon, D. T. A., \& Blake, R. L. (1993) Does problem-based learning work? A meta-analysis of evaluative research. Academic Medicine, 68(7), 550-563. 